\title{
Leydig Cells Undergoing Apoptosis in the Perinatal Rat Testis
}

\author{
Hiromichi Yokoi ${ }^{1}$, Yoshihiro Yamama ${ }^{1}$, Yoshihiro Tsuruo ${ }^{1}$, Yoshihiko Kawarada ${ }^{2}$, \\ Naoyuki Miura ${ }^{2}$, Toshihiro Sugiyama ${ }^{2}$ and Kazunori Ishimura ${ }^{1}$ \\ 'Department of Anatomy and Cell Biology, The University of Tokushima School of Medicine, Tokushima 770-8503 \\ and 'Department of Biochemistry, Akita University School of Medicine, Akita 010-8543
}

Received for publication March 20, 1998 and in revised form July 27, 1998

\begin{abstract}
It has been suggested that fetal Leydig cells in rat testes decrease in number just before or soon after birth. However, recent studies have indicated that during the perinatal period, the total number of the Leydig cells does not significantly change. The present study examined apoptotic cell death in the rat testis from embryonic day 18 to postnatal day 49. Apoptotic cells were examined by immunohistochemistry with an antibody against single-stranded DNA (ssDNA), and in situ terminal deoxynucleotidyl transferase staining (in situ TdT). During the perinatal period, ssDNA-immunopositive cells and in situ TdT-positive cells were scattered in the interstitium but were barely present in the
\end{abstract}

seminiferous tubules. After postnatal day 7 , the positive cells were abundant in the seminiferous tubules but scarce in the interstitium. Double-immunostaining for ssDNA and a steroidogenic enzyme, P450c17, demonstrated that parts of P450c17positive Leydig cells were ssDNA-positive. Electron microscopic observations revealed that in situ TdT-positive cells had characteristic features of Leydig cells. These results suggest that fetal Leydig cells undergo apoptosis during the perinatal period, and that the number of Leydig cells is regulated by both the rate of cell proliferation and apoptotic cell death.

Key words: Rat testis, Apoptosis, Single-stranded DNA, In situ TdT, Electron microscopy

\section{Introduction}

Testosterone production in rat testes changes markedly in various developmental stages. During the final third stage of gestation, the production increases and reaches a maximum on the 19th embryonic day (E19); then, it decreases and reaches a minimum at about 14 days after birth. Thereafter, it increases again and attains adult levels by 60 days after birth $[3,7,19]$. These two phases of androgen-producing activity correlate with two distinct Leydig cell types, fetal and adult Leydig cells $[6,13,15]$.

In the perinatal period of the rat, the fetal Leydig cells have been assumed to decrease in number just before or soon after birth, and accordingly, reduce testosterone production $[13,15,17]$. However, recent studies have indicated that the total number of fetal Leydig cells in testes

Selected by "The 38th Annual Meeting of the Japan Society of Histochemistry and Cytochemistry" held in Mitaka, Japan on Oct. 16-17, 1997.

Correspondence to: Dr. Kazunori Ishimura, Department of Anatomy and Cell Biology, The University of Tokushima School of Medicine, Tokushima 770-8503, Japan. does not markedly change between the end of pregnancy and the beginning of the neonatal period, and that fetal Leydig cells persist even in adult testes $[9,11,21]$.

To elucidate the fate of fetal Leydig cells, the present study examined apoptotic cell death in rat testes from E18 to 7 weeks after birth.

Apoptotic cell death in germ cells of the postnatal rat testes has previously been examined. The level of apoptotic DNA fragmentation is age-dependent and peaks in 16- to 28-day-old rats; apoptotic cells are preferentially found in spermatogenesis-stages I and XII-XIV; spermatocyte is the major cell type undergoing apoptosis [1]. Apoptosis in the fetal and neonatal rat testes, however, has not been extensively examined.

In situ 3' end-labeling of DNA fragmentation by terminal deoxynucleotidyl transferase (in situ TdT) is routinely used to detect apoptotic cells in various tissues including the testis $[1,4]$. Recently, the antibody against single-stranded DNA (ssDNA) has been demonstrated to be a good marker of drug-induced apoptosis and programmed cell death during embryogenesis [14], and to recognize ssDNA with various base sequences [8]. Furthermore, electron microscopy is essential for confirming 
the morphological characteristics of apoptotic cells. Using these methods we detected apoptosis in the fetal and postnatal rat testes.

\section{Materials and Methods}

\section{Experimental animals and tissue preparation}

Fetal, neonatal and adult male Wistar rats (Japan SLC, Shizuoka, Japan) were used. The day when spermatozoa were found in the vaginal smear was designated as embryonic day zero (E0). The day of birth, usually E22, was designated as postnatal day zero (P0). The animals were maintained on a 12-hr light-dark cycle at $20^{\circ} \mathrm{C}$ and fed lab chow and water ad libitum.

On gestational days 18 and 21 (E18 and E21), pregnant rats were sacrificed by cervical dislocation and the fetuses were removed. The testes of the embryos were immediately placed in ice-cold fixative consisting of 4\% paraformaldehyde in $0.1 \mathrm{M}$ phosphate buffer (PB) (pH 7.4) and kept overnight at $4^{\circ} \mathrm{C}$. The testes of male newborns on P1 were removed under anesthesia by intraperitoneal injection (i.p.) of pentobarbital sodium (25 $\mathrm{mg} / \mathrm{kg}$ body weight) and immersed in the fixative overnight at $4^{\circ} \mathrm{C}$. The male rats at later postnatal ages $(P 7$, P21 and P49) were perfused through the left ventricle with warmed $\left(37^{\circ} \mathrm{C}\right)$ heparinized $0.1 \mathrm{M} \mathrm{PB}(\mathrm{pH} 7.4)$, followed by the fixative under anesthesia (pentobarbital sodium $50 \mathrm{mg} / \mathrm{kg}$ body weight, i.p.). The excised testes were immersed in the same fixative overnight at $4^{\circ} \mathrm{C}$. After fixation, some of the tissues were dehydrated in ethanol and embedded in paraffin blocks, and others were soaked in $10 \%, 15 \%$ and $20 \%$ sucrose in $0.01 \mathrm{M}$ phosphate-buffered saline (PBS), pH 7.4, and frozen in O.C.T. Compound (Tissue-Tek, Sakura Finetechnical Co., Ltd., Tokyo, Japan).

\section{Immunohistochemistry}

The paraffin-embedded sections $6 \mu \mathrm{m}$ in thickness were cut, mounted on glass slides coated with chrome alum gelatin, and air-dried overnight at $37^{\circ} \mathrm{C}$. The sections were deparaffinized and then rehydrated in water. The frozen sections $8 \mu \mathrm{m}$ in thickness were cut, mounted on gelatin coated slides and dried for about $1 \mathrm{hr}$. These sections were soaked in $0.2 \%$ Triton X-100 in 0.01 M PBS for $20 \mathrm{~min}$. Endogenous peroxidase was blocked by incubation with $3 \%$ hydrogen peroxide in distilled water for $20 \mathrm{~min}$ at room temperature, and endogenous avidin/biotin binding was blocked with avidin $\mathrm{D}$, followed by biotin (Vectastain, Vector, USA). The paraffin sections were then incubated overnight with the antiserum against single-stranded DNA (ssDNA) $[8,14,20]$ diluted $1: 1,000$ in $0.01 \mathrm{M}$ PBS containing $1 \%$ normal goat serum (NGS) at $4^{\circ} \mathrm{C}$. The frozen sections were incubated overnight with the antiserum against cytochrome P450 of $17 \alpha$-hydroxylase/C17,20-lyase (P450c17) (provided by Dr. Kominami, Faculty of Integrated Arts and Sciences, Hiroshima University, Hiroshima, Japan) $[10,16]$ diluted $1: 4,000$ in
$0.01 \mathrm{M}$ PBS containing $1 \%$ NGS at $4^{\circ} \mathrm{C}$. Thereafter, the sections were incubated with biotinylated goat anti-rabbit IgG diluted $1: 100$ in $0.01 \mathrm{M}$ PBS containing 1\% NGS for $1 \mathrm{hr}$ at $32^{\circ} \mathrm{C}$, followed by streptavidin-peroxidase (Histofine, Nichirei, Japan) for $1 \mathrm{hr}$ at $32^{\circ} \mathrm{C}$. Immunoreactivity was visualized in $50 \mathrm{mM}$ TRIS- $\mathrm{HCl}$ buffer, $\mathrm{pH}$ 7.6, containing $0.01 \% 3,3$ '-diaminobenzidine tetrahydrochloride (DAB) and $0.01 \%$ hydrogen peroxide, and examined by light microscopy.

As the control, some sections were incubated with normal rabbit serum in place of the antiserum against ssDNA or P450c17.

\section{Double immunolabeling}

Some paraffin-embedded sections were double-immunostained for ssDNA and P450c17. The sections were incubated with antiserum against ssDNA $(1: 1,000)$ overnight at $4^{\circ} \mathrm{C}$. Then, the sections were incubated with biotinylated goat anti-rabbit $\operatorname{IgG}(1: 100)$ for $1 \mathrm{hr}$ at $32^{\circ} \mathrm{C}$, followed by streptavidin-peroxidase (Histofine, Nichirei, Japan) for $1 \mathrm{hr}$ at $32^{\circ} \mathrm{C}$. The immunoreaction was first visualized (brown color) in $50 \mathrm{mM}$ TRIS-HCl buffer, pH 7.6, containing $0.01 \%$ DAB and $0.01 \%$ hydrogen peroxide. After washing with $0.01 \mathrm{M}$ PBS, the sections were incubated overnight with antiserum against $\mathrm{P} 450 \mathrm{cl} 7$ $(1: 4,000)$ at $4^{\circ} \mathrm{C}$, followed by biotinylated goat antirabbit IgG $(1: 100)$ for $1 \mathrm{hr}$ at $32^{\circ} \mathrm{C}$, and finally with streptavidin-peroxidase (Histofine, Nichirei, Japan) for 1 $\mathrm{hr}$ at $32^{\circ} \mathrm{C}$. Immunoreactivity for $\mathrm{P} 450 \mathrm{c} 17$ was visualized (purple color) in $50 \mathrm{mM}$ TRIS-HCl buffer, $\mathrm{pH} 7.6$, containing $0.01 \%$ 4-chloro-1-naphthol and $0.01 \%$ hydrogen peroxide.

\section{In situ $T d T$ reaction}

We used an ApopTag Plus-peroxidase kit (Oncor, Gaithersburg, MD). In brief, this kit uses terminal deoxynucleotidyl transferase (TdT) to catalyze the templateindependent addition of digoxigenin-dUTP and dATP to 3'-OH ends of fragmented DNA. The incorporated nucleotides form a random heteropolymer of digoxigenindUTP and AATP, and then an anti-digoxigenin antibody conjugated to peroxidase is added.

In practice, the paraffin-embedded sections were deparaffinized, rehydrated, and soaked in $0.2 \%$ Triton X100 in $0.01 \mathrm{M}$ PBS for $20 \mathrm{~min}$. Endogenous peroxidase was blocked by incubation with 3\% hydrogen peroxide in $0.01 \mathrm{M}$ PBS for $20 \mathrm{~min}$ at room temperature. The sections were then incubated with a mixture of digoxigeninconjugated nucleotides and $\mathrm{TdT}$ at $37^{\circ} \mathrm{C}$ for $3 \mathrm{hr}$, and subsequently treated with anti-digoxigenin conjugated to peroxidase at $37^{\circ} \mathrm{C}$ for $30 \mathrm{~min}$. Immunoreactivity was visualized in $50 \mathrm{mM}$ TRIS- $\mathrm{HCl}$ buffer, $\mathrm{pH} \mathrm{7.6,} \mathrm{containing}$ $0.01 \% \mathrm{DAB}$ and $0.01 \%$ hydrogen peroxide. As the control, some sections were incubated without TdT.

\section{Electron microscopy}

Frozen sections were examined by ssDNA-immuno- 
histochemistry and in situ TdT staining, without incubation with $0.2 \%$ Triton $\mathrm{X}-100$. After the peroxidase reaction, the DAB chromogen was intensified with silvergold [12]. After intensification, the sections were treated with $1 \%$ osmium tetroxide for $1 \mathrm{hr}$ at room temperature, rinsed with $10 \%$ sucrose in distilled water, stained with a saturated solution of uranyl acetate for $30 \mathrm{~min}$ at room temperature, rinsed with $10 \%$ sucrose in distilled water, dehydrated in a graded series of ethanol, and embedded in Epon. Ultrathin sections were cut on a Reichert Ultracut E, mounted on copper grids, and examined using a Hitachi H-500 electron microscope.

\section{Results}

In the paraffin sections of fetal rat testes on E18 and E21, ssDNA-immunoreactive cells and in situ TdTpositive cells were abundant in the interstitium of the testis, and scarce in the immature seminiferous tubules (Fig. 1a, b, d, e). On P1, ssDNA- and in situ TdT-positive cells were also scattered in the interstitium (Fig. 1g, h). However, on P7, ssDNA- or in situ TdT-positive cells were rarely localized in the interstitium and occasionally observed in the seminiferous tubules (Fig. 2a, b). On P21, many positive cells for ssDNA and in situ TdT were present in the seminiferous tubules with some developed structures (Fig. 2d, e). On P49, a few of the ssDNA- and in situ TdT-positive cells were observed in the mature seminiferous tubules (Fig. $2 \mathrm{~g}, \mathrm{~h}$ ).

Immunoreactive cells for $\mathrm{P} 450 \mathrm{c} 17$, a steroidogenic enzyme and a maker of Leydig cells, were observed in the interstitium of the testis in the frozen sections. Many immunoreactive cells were observed in fetal and neonatal rat testes (Fig. 1). They decreased in number per section and showed cluster-formation on P7 (Fig. 2c). On P21 and P49, the immunopositive cells increased (Fig. 2f, i).

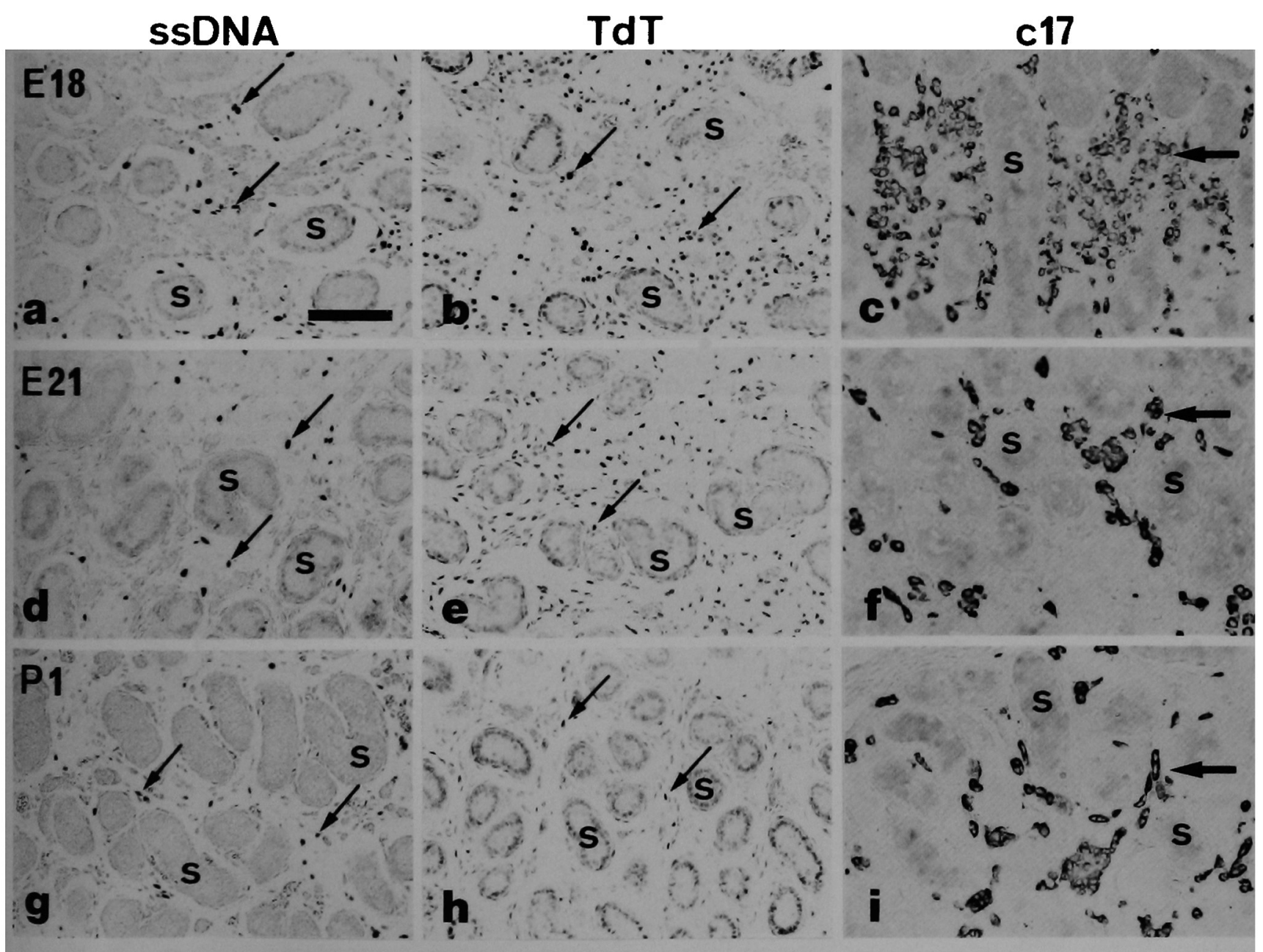

Fig. 1. Staining of ssDNA (a, d, g), in situ TdT (b, e, h), and P450c17 (c, f, i) in the rat testis on E18 (a-c), E21 (d-f) and P1 (g-i). ssDNA-immunopositive cells (left column: ssDNA, a, d, g) and in situ TdT-positive cells (middle column: TdT, b, e, h) are mainly localized in the interstitium of the testis, and scarce in the seminiferous tubules that show immature structure at these fetal and neonatal stages. Immunoreactivity for P450c17 (right column: c17, c, f, i) is localized in the cytoplasm of the interstitial cells in the testis. P450c17-positive cells in the sections on E21 or P1 seem to decrease in number as compared with those on E18. Positive cells are indicated with arrows. S, seminiferous tubules. $\mathrm{Bar}=100 \mu \mathrm{m}$. 


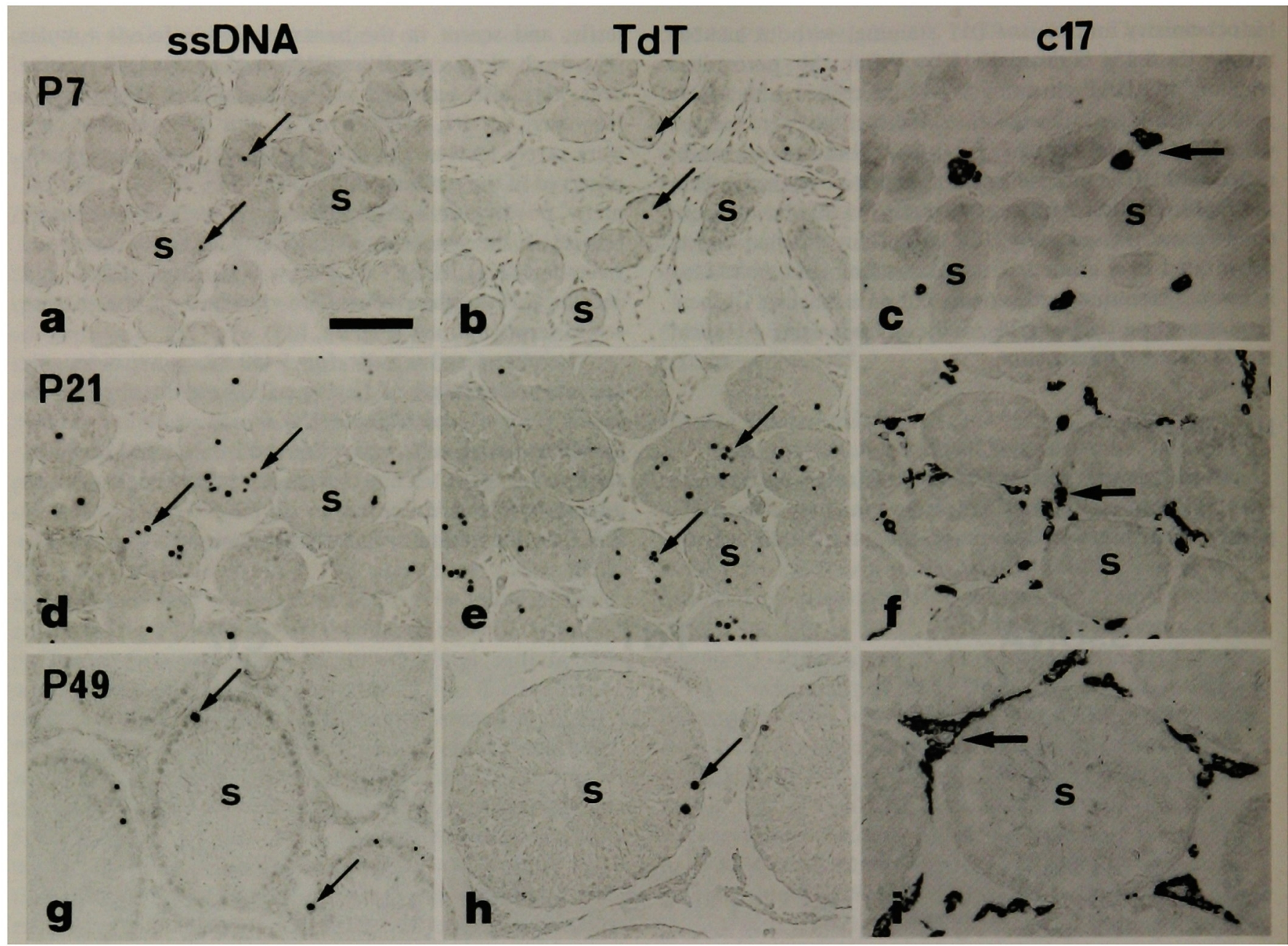

Fig. 2. Staining of ssDNA (a, d, g), in situ TdT (b, e, h), and P450c17 (c, f, i) in the rat testis on P7 (a-c), P21 (d-f) and P49 (g-i). First row (a-c): on P7, ssDNA-immunoreactive cells (a) and in situ TdT-positive cells (b) are occasionally observed in the seminiferous tubules and rare in the interstitium; P450c17-immunopositive cells (c) mostly form clusters and are scattered in the interstitium. Second row (d-f): on P21, many positive cells for ssDNA (d) and in situ TdT (e) are localized in the seminiferous tubules that show a developing structure; P450c17-immunopositive cells (f) are increased in number in the interstitium. Third row (g-i): on P49, ssDNA- (g) or in situ TdT-positive (h) cells are occasionally localized in the seminiferous tubules with mature structure. P450c17-positive cells increase in number (i). Positive cells are indicated with arrows. $\mathrm{s}$, seminiferous tubules. Bar $=100 \mu \mathrm{m}$.

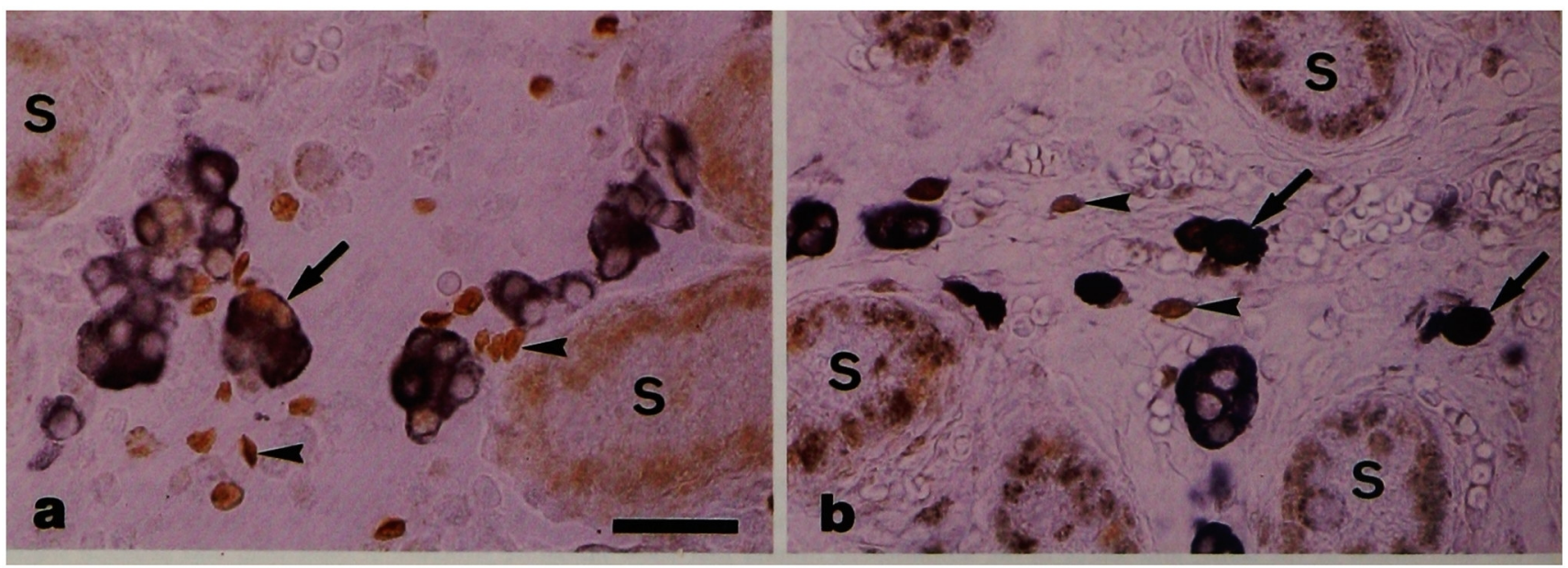

Fig. 3. Double immunostaining of ssDNA and P450c17 in the rat testis on P1 (a, b). Some of the P450c17-immunopositive cells (bluish purple) contain ssDNA-immunoreactivity (brown) in their cell nuclei (arrows). Some ssDNA-positive nuclei are spindle-shaped (arrowheads). s, seminiferous tubules. Bar $=30 \mu \mathrm{m}$. 
There was no reaction in the control sections incubated with normal rabbit serum or incubated without the TdT enzyme (data not shown).

The immunoreactivity of ssDNA was observed in the nuclei, and the P450c17 immunoreactivity was found in the cytoplasm (Fig. 3). The ssDNA-positive nuclei were round or spindle-shaped. Double immunostaining of ssDNA and P450c17 demonstrated that some of the P450c17-immunopositive Leydig cells contained ssDNA immunoreactivity in the nuclei (Fig. 3).

Although immunocytochemistry of ssDNA was not successful in the frozen sections, in situ TdT-positive cells in the fetal and neonatal rat testes were observed by electron microscopy using the silver-gold intensification and pre-embedding method. Silver grains corresponding to the DAB chromogen were present in fragmented nuclei with condensed chromatin (Fig. 4). The grains were preferentially deposited on the surface of the nucleus. In Fig. 4a, lipid droplet-like small vesicles were observed in the shrunk cytoplasm surrounding the fragmented nucleus. Fig. 4b showed that in situ TdT-positive nuclei with condensed chromatin were phagocytosed by a cell with a bean-shaped nucleus.

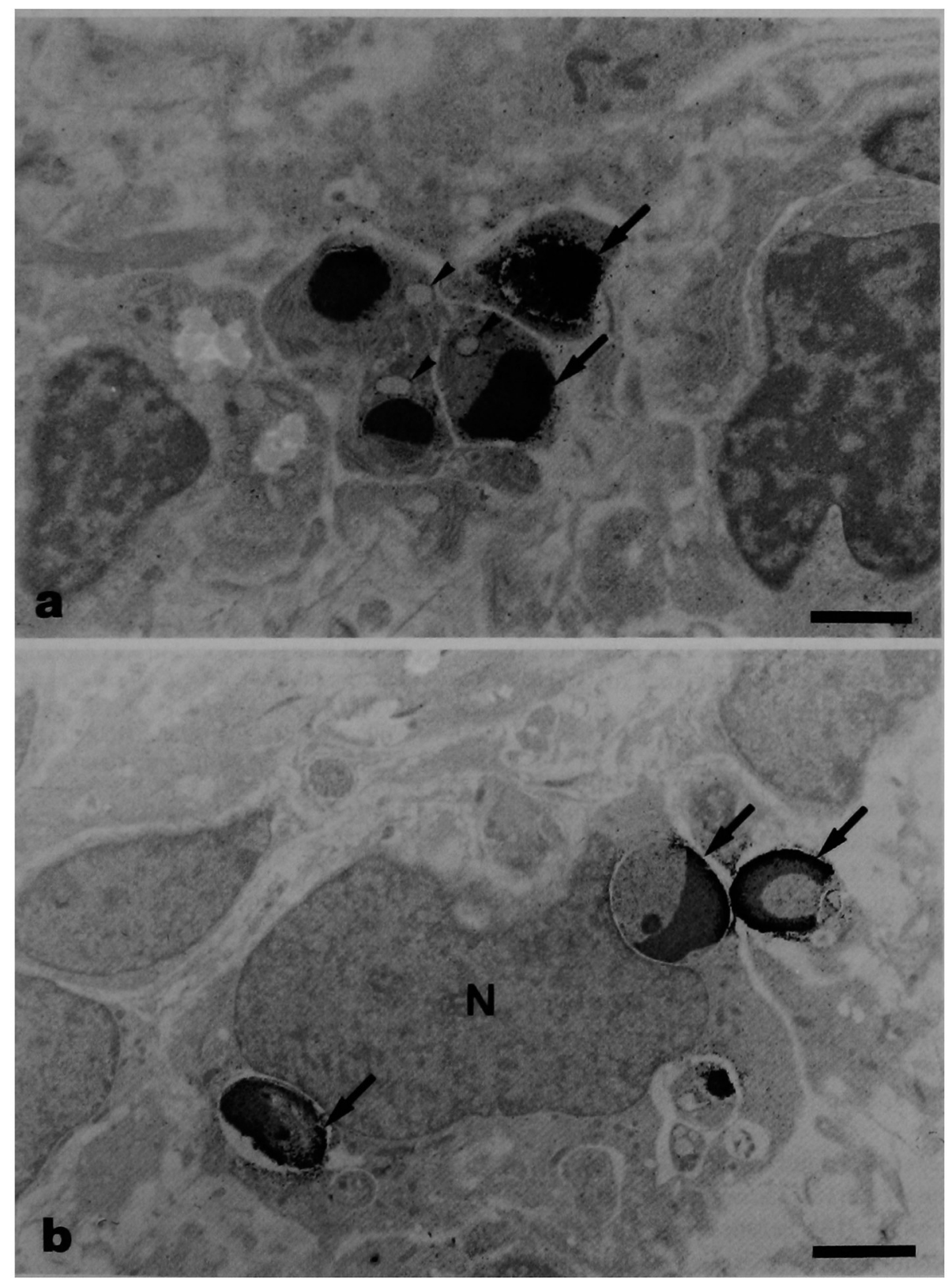

Fig. 4. Electron micrograph of in situ TdT-positive cells in the rat testis on P1. a: Silver grains, which correspond to the location of the DAB endproducts, are present in the fragmented nucleus with condensed chromatin (arrows). Small lipid droplets (arrowheads) are observed in the shrunk cytoplasm surrounding the fragmented nucleus. b: Silver grains are also observed in the nuclei with condensed chromatin (arrows). Some of these in situ TdT-positive nuclei are phagocytosed by a cell with a bean-shaped nucleus (N). Bars $=2 \mu \mathrm{m}$ (a), $3 \mu \mathrm{m}$ (b). 


\section{Discussion}

This study has demonstrated that ssDNA-immunoreactive and in situ $\mathrm{TdT}$-positive cells are preferentially localized in the interstitium of the testes of fetal and neonatal rats. Parts of the ssDNA-immunopositive cells also possessed P450c17-immunoreactivity in the cytoplasm. These results suggest that some fetal Leydig cells undergo apoptotic cell death.

Fetal Leydig cells of rats were believed to decrease in number just before or soon after birth [13, 15, 17]. However, recent studies have indicated that the total number of fetal Leydig cells does not change markedly in the perinatal period, even though the number of Leydig cells per unit volume decreases $[9,11,21]$. The present study has demonstrated apoptosis of fetal Leydig cells, and suggests that fetal Leydig cells keep a balance between cell proliferation and cell death in the perinatal period, and that consequently the total number of the Leydig cells does not change.

In the adolescent and adult rat testes, cells in the interstitium rarely expressed ssDNA- or in situ TdT-reactivity (Fig. 2). This difference in frequency of apoptosis may be of a different character which lies between fetal and adult Leydig cells. Apoptotic cell death of germ cells in the postnatal rat testis has already been elucidated [1].

There were some ssDNA-positive and P450c17-negative cells in the interstitium of fetal and neonatal rat testes (Fig. 3). Parts of these cells had round nuclei and may be Leydig cells with shrunk cytoplasm undergoing apoptosis. Other cells have demonstrated spindle-shaped nuclei and may be fibroblasts or Leydig cells with shrunk nucleus and cytoplasm. We could not determine the characteristics of these cells in this study. Further electron microscopic study is needed to elucidate the characteristics of ssDNApositive and P450c17-negative cells.

The antibody against single-stranded DNA has been recently demonstrated to be a marker of drug-induced apoptosis and programmed cell death during embryogenesis [14]. It is suggested that degradation of the supercoiling organization of DNA to single strands is one of the DNA degradation steps during apoptosis and programmed cell death as well as of oligonucleosomal fragmentation [14]. The present study has demonstrated that ssDNAimmunopositive cells have nearly identical localization and number as in situ TdT-positive cells at all stages of development. These results suggest that ssDNA-immunohistochemistry detects apoptotic nuclei as effectively as in situ TdT-staining.

Apoptotic cell death is usually confirmed by electron microscopic detection of nuclear chromatin condensation and cytoplasmic shrinkage [18], because in situ TdT-positive cells are occasionally necrotic cells such as those in the liver of $\mathrm{CCl}_{4}$-injected rat [5]. This study has confirmed the apoptotic characteristics of the cells in the interstitium of perinatal rat testes using the in situ $\mathrm{TdT}$ and the silvergold intensification method [12]. The intensification method facilitated the detection of in situ $\mathrm{TdT}$-positive cells as shown in Fig. 4. These positive cells may be apoptotic bodies, which are shrunk apoptosis-cells splitting into small membrane-bounded bodies [18]. Because lipid droplet-like vesicles are found in these apoptotic bodies (Fig. 4a), the bodies may be derived from fetal Leydig cells. Apoptotic bodies are usually phagocytosed by macrophages and neighboring cells. The phagocytosis is shown in Fig. 4b, and the phagocyte may be a macrophage because of its characteristic bean-shaped nucleus. Recently, Collins et al. [2] has demonstrated that in situ nick-translation signals are localized around apoptotic nuclear fragments, and that they have a circular or ring pattern. The silver grains in Fig. 4 are also located in the periphery of the nucleus with condensed chromatin. DNA fragmentation of the apoptotic nucleus may preferentially occur in the periphery of the nucleus.

In summary, this study has shown that apoptotic cells are localized in the interstitium of perinatal rat testis. These results suggest that fetal Leydig cells undergo apoptosis, and that the number of fetal Leydig cells is regulated by the balance between cell proliferation and apoptotic cell death.

\section{Acknowledgments}

We wish to thank A. Kasai for her secretarial assistance.

\section{References}

1. Billig, H., Furuta, I., Rivier, C., Tapanainen, J., Parvinen, M. and Hsueh, A. J.: Apoptosis in testis germ cells: developmental changes in gonadotropin dependence and localization to selective tubule stages. Endocrinology 136; 5-12, 1995.

2. Collins, J. A., Schandi, C. A., Young, K. K., Vesely, J. and Willingham, M.C.: Major DNA fragmentation is a late event in apoptosis. J. Histochem. Cytochem. 45; 923-934, 1997.

3. El-Gehani, F., Zhang, F. P., Pakarinen, P., Rannikko, A. and Huhtaniemi, 1.: Gonadotropin-independent regulation of steroidogenesis in the fetal rat testis. Biol. Reprod. 58; 116123, 1998.

4. Gavrieli, Y., Sherman, Y. and Ben, S. S.: Identification of programmed cell death in situ via specific labeling of nuclear DNA fragmentation. J. Cell Biol. 119; 493-501, 1992.

5. Hashimoto, S., Koji, T., Niu, J., Kanematsu, T. and Nakane, P. K.: Differential staining of DNA strand breaks in dying cells by non-radioactive in situ nick translation. Arch. Histol. Cytol. 58; 161-170, 1995.

6. Huhtaniemi, I. T., Katikineni, M. and Catt, K. J.: Regulation of luteinizing-hormone-receptors and steroidogenesis in the neonatal rat testis. Endocrinology 109; 588-595, 1981.

7. Huhtaniemi, I. T., Nozu, K., Warren, D. W., Dufau, M. L. and Catt, K. J.: Acquisition of regulatory mechanisms for gonadotropin receptors and steroidogenesis in the maturing rat testis. Endocrinology 111; 1711-1720, 1982.

8. Kawarada, Y., Miura, N. and Sugiyama, T.: Antibody against single-stranded DNA useful for detecting apoptotic cells recognized hexadeoxynucleotides with various base sequences. $J$. Biochem. 123; 492-498, 1998.

9. Kerr, J. B. and Knell, C. M.: The fate of fetal Leydig cells 
during the development of the fetal and postnatal rat testis. Development 103; 535-544, 1988.

10. Kominami, S., Shinzawa, K. and Takemori, S.: Purification and some properties of cytochrome $\mathrm{P}-450$ specific for steroid $17 \alpha$-hydroxylation and $\mathrm{C} 17-\mathrm{C} 20$ bond cleavage from guinea pig adrenal microsomes. Biochem. Biophys. Res. Commun. 109; 916-921, 1982.

11. Kuopio, T., Tapanainen, J., Pelliniemi, L. J. and Huhtaniemi, I.: Developmental stages of fetal-type Leydig cells in prepubertal rats. Development 107; 213-220, 1989.

12. Liposits, Z., Setalo, G. and Flerko, B.: Application of the silver-gold intensified 3,3'-diaminobenzidine chromogen to the light and electron microscopic detection of the luteinizing hormone-releasing hormone system of the rat brain. Neuroscience 13; 513-525, 1984.

13. Lording, D. W. and De, K. D.: Comparative ultrastructural and histochemical studies of the interstitial cells of the rat testis during fetal and postnatal development. J. Reprod. Fertil. 29; 261-269, 1972.

14. Naruse, I., Keino, H. and Kawarada, Y.: Antibody against single-stranded DNA detects both programmed cell death and drug-induced apoptosis. Histochemistry 101; 73-78, 1994.

15. Roosen-Runge, E. C. and Anderson, D.: The development of the interstitial cells in the testis of the albino rat. Acta Anat.
37; 125-137, 1959.

16. Shinzawa, K., Ishibashi, S., Murakoshi, M., Watanabe, K. Kominami, S., Kawahara, A. and Takemori, S.: Relationship between zonal distribution of microsomal cytochrome P-450s (P-45017 $\alpha$, lyase and $\mathrm{P}-450 \mathrm{C} 21)$ and steroidogenic activities in guinea-pig adrenal cortex. J. Endocrinol. 119; 191-200, 1988.

17. Tapanainen, J., Kuopio, T., Pelliniemi, L. J. and Huhtaniemi, I.: Rat testicular endogenous steroids and number of Leydig cells between the fetal period and sexual maturity. Biol. Reprod. 31; 1027-1035, 1984.

18. Uchiyama, Y.: Apoptosis: The history and trends of its studies. Arch. Histol. Cytol. 58; 127-137, 1995.

19. Warren, D. W., Haltmeyer, G. C. and Eik, N. K.: Testosterone in the fetal rat testis. Biol. Reprod. 8; 560-565, 1973.

20. Yamada, H., Hirai, S., Ikegami, S., Kawarada, Y., Okuhara, E. and Nagano, H.: The fate of DNA originally existing in the zygote nucleus during achromosomal cleavage of fertilized echinoderm eggs in the presence of aphidicolin: microscopic studies with anti-DNA antibody. J. Cell Physiol. 124; 9-12, 1985.

21. Zirkin, B. R. and Ewing, L. L.: Leydig cell differentiation during maturation of the rat testis: a stereological study of cell number and ultrastructure. Anat. Rec. 219; 157-163, 1987. 